\title{
A ótica dos atores sociais na gestão ambiental dos terrenos de marinha: o caso da orla do canal da Barra da Lagoa, Ilha de Santa Catarina, Brasil
}

\section{Social actors'perceptions in the management of shoreline land: the case of the seafront of Barra da Lagoa'channel, Island of Santa Catarina, Brazil}

\author{
Neres de Lourdes da Rosa BITTENCOURT* \\ Eduardo Juan SORIANO-SIERRA*
}

\begin{abstract}
RESUMO
O presente estudo trata da gestão ambiental dos terrenos de marinha através da investigação da percepção de atores sociais com influência no uso e ocupação da orla do canal da Barra da Lagoa, localizado na Ilha de Santa Catarina, Brasil. Os procedimentos metodológicos envolveram observações em campo e entrevistas estruturadas com atores sociais. Observaram-se usos e ocupações irregulares. Conforme entrevistas realizadas na comunidade local, perceberam-se conflitos de interesses, incluindo insatisfação quanto à privatização do domínio público marítimo, descrédito sobre os atores institucionais com atribuições na área e falta de conhecimento dos instrumentos de regulamentação por parte de atores sociais. O presente estudo visa contribuir para o debate sobre a preservação da orla marítima, questão que é de grande importância na sociedade contemporânea.

Palavras-chave: atores sociais; gestão ambiental; terrenos de marinha; canal lagunar; Ilha de Santa Catarina.
\end{abstract}

\begin{abstract}
The present study addresses the environmental management of shoreline land through the investigation of the social actors' perceptions who have influence on the use and occupation of the seafront of Barra da Lagoa's channel, located in the Island of Santa Catarina, Brazil. The methodological procedures
\end{abstract}


involved field observation and structured interviews with social actors. It was evidenced irregular use and occupation. According to the interviews with the local community, it was observed interest conflicts, dissatisfaction regarding the privatization of the maritime public domain, discredit on the institutional actors who have attributions in the area, and lack of knowledge of instruments of regulation on the part of the social actors. This study presents a contribution to the society, as it addresses the preservation of the seafront, which is a space of high significance for thousands of people.

Key words: social actors; environmental management; shoreline land; lagoon channel; Island of Santa Catarina.

\section{Introdução}

Os espaços costeiros brasileiros, incluindo os de marinha, passam atualmente por um processo de urbanização agressivo e expansivo, provocando sua depreciação e degradação, com ocupação e uso inadequado e inconseqüente do território.

No presente, a gestão desses espaços, busca promover a garantia do uso sustentável desta estreita faixa costeira que comporta ecossistemas de extrema fragilidade e importância para a manutenção da biodiversidade, incluindo praias, manguezais, marismas, dunas, restingas e promontórios, nos quais existem ainda sítios arqueológicos que testemunham a sua ocupação pré-histórica.

A orla marítima e os terrenos de marinha sempre foram importantes para o país. Entretanto, no passado a ênfase era dada à defesa nacional, sendo que hoje é voltada para o uso e ocupação pela população, precisando assim, de ações de gerenciamento costeiro buscando harmonizar o anseio humano, com a urgente necessidade de considerar a proteção das áreas naturais remanescentes, que na maioria dos casos, encontram-se fragilizados.

Mesmo que os temas relacionados às questões ambientais tenham ganhado espaço nos últimos anos, os ecossistemas existentes na orla marítima ainda são motivos de conflitos múltiplos em todo o litoral brasileiro. Isso acontece por constituírem, de um lado, áreas de grande procura pelo turismo e, de outro, de oferta da infra-estrutura que o visitante procura, incluindo restaurantes, bares, hotéis, lojas entre outros estabelecimentos comerciais e, conseqüentemente, também para especulação imobiliária, a que é desordenada em quase toda a costa.

Neste cenário enquadra-se o canal da Barra da Lagoa, que se destaca na paisagem da Ilha de Santa Catarina pela sua beleza natural e por oferecer serviços essenciais e lazer para os moradores locais e turistas, além de servir como via de circulação para embarcações de turismo e das pescas artesanal, industrial e esportiva. Apesar dos atributos naturais e antrópicos que caracterizam as peculiaridades do local, este é cenário de conflitos de interesses múltiplos, relacionados ao uso e ocupação do bem de domínio público.

Neste contexto, o presente estudo visa investigar a ótica dos atores sociais quanto à conservação ambiental dos terrenos de marinha localizados na orla do canal lagunar. Para tanto, foram feitos registros em campo sobre uso e ocupação da orla, bem como entrevistas estruturadas com diversos atores sociais, incluindo governamentais e não governamentais envolvidos com a problemática dos conflitos na área costeira de domínio público.

\section{Terrenos de marinha}

A Constituição da República enfatiza que a Zona Costeira é uma "porção do território brasileiro sob proteção ambiental especial”. Consta no Artigo 225 que a Zona Costeira é

[...] patrimônio nacional, e sua utilização far-se-á, na forma da lei, dentro de condições que assegurem a preservação do meio ambiente, inclusive quanto ao uso dos recursos naturais (BRASIL, 1998).

Por definição, conforme o Decreto n. ${ }^{\circ}$ 9.760/46, os terrenos de marinha constituem os espaços territoriais que se situam em uma faixa de 33 metros, medidos horizontalmente, para a parte da terra, da posição da linha da preamar média - LPM - de 1831. São formados naturalmente pela ação dos ventos e das águas ou artificialmente e estão localizados na costa marítima do litoral brasileiro, no continente e nas 
margens dos rios e lagoas, até onde ocorre influência das marés (BRASIL, 1946). Na Instrução $n .^{\circ} 81$ consta que:

A linha da preamar média de 1831 é determinada pela interseção do plano horizontal que contém o ponto definido pela cota básica, com o terreno, considerandose, caso tenha ocorrido qualquer modificação, sua configuração primitiva (sANTOS, 1985, p. 122).

Ainda, segundo Di Pietro (1994), o ponto de demarcação destes terrenos refere-se ao estado do lugar no tempo da execução do artigo $15, \S 4^{\circ}$, da Lei de 15 de novembro de 1831.

O surgimento dos "terrenos de marinha" no Brasil se deve às Ordenações portuguesas, regimento que foi estabelecido no Brasil no período colonial. Neste período, as terras pertenciam ao domínio de Portugal. Embora não tenha sido utilizado o termo "terrenos de marinha" naquele país. O termo "marinha", apareceu pela primeira vez na Ordem Régia de 21 de outubro de 1710, sendo este considerado o primeiro documento que chegou ao Brasil e que mencionou o termo. O que hoje é conhecido por terrenos de marinha permanecia sob a tutela direta da Família Real ou do Estado. Entre as terras que eram colonizadas por terceiros não constavam as lizeiras conhecidas por marinhas, mas foi a Lei Orçamentária de 15 de novembro de 1831, a primeira lei que tratou das terras de marinha de forma expressiva (SANTOS, 1985; PUGLIESE, 2006).

No Brasil, os terrenos de marinha tiveram sua origem na cidade do Rio de Janeiro por volta do século XVII. A finalidade destas terras de marinha se deu com base na necessidade de

[...] serviços de embarque e desembarque de coisas públicas ou particulares, para a defesa da cidade e para a obtenção de renda, além de algumas vezes se prestarem para a extração de sal (GASPARINI, 1992, p. 523).

Por serem terras de fronteira com o mar, foi objetivando a defesa do território que se atribuiu a importância destas.

Segundo Cazetta (2002), os terrenos e acrescidos de marinha são terras públicas e se incluem entre os bens dominiais da União. Meirelles (1994, p. 430) esclarece que:
Bens públicos, em sentido amplo, são todas as coisas, corpóreas ou incorpóreas, imóveis e semoventes, créditos, direitos e ações, que pertençam, a qualquer título, às entidades estatais, autárquicas, fundações e paraestatais.

Esclarece ainda que, são públicos os bens do domínio nacional, pertencentes à União, aos Estados e aos Municípios.

\section{Gestão dos terrenos de marinha}

Segundo Cazetta (2002), os terrenos e acrescidos de marinha podem ser transferidos a particulares através de aforamento, pois são bens dominiais ou disponíveis. Conforme o Código Civil, lei n. ${ }^{\circ} 10.406$ de 2002, são bens públicos: “[...] os dominiais, que constituem o patrimônio das pessoas jurídicas de direito público, como objeto de direito pessoal, ou real, de cada uma dessas entidades".

Assim, os terrenos de marinha são cedidos pela União a terceiros para uso e ocupação por meio de aforamento que é o direito de usufruir o imóvel através do pagamento à União de uma pensão anual denominada foro. $\mathrm{O}$ aforamento pode acontecer quanto não existir interesses público, econômico ou social manifesto sobre o terreno. Quando, por parte da União, não houver interesse econômico ou social em manter o imóvel, então, particulares podem adquiri-lo através de alienação que deve ser feita por meio de licitação. Importante salientar que, os terrenos de marinha podem ser doados pela União para habitação de interesse social (SAULE JÚNIOR et al., 2006).

De acordo com a lei n. ${ }^{\circ} 11.481 / 07$, a Secretaria do Patrimônio da União do Ministério do Planejamento, Orçamento e Gestão tem responsabilidades pelo processo de fiscalização, identificação, demarcação, cadastramento e a regularização dos terrenos de marinha, sendo permitida a atuação dos municípios através de convênio ou contrato com a Secretaria do Patrimônio da União (BRAsIL, 2007).

Atualmente, os terrenos de marinha estão passando por um processo de regularização fundiária, através de um instrumento criado para promover a gestão integrada, o "Projeto de Gestão Integrada da Orla Marítima - Projeto Orla", coordenado pelo Ministério do Meio Ambiente e pela Secretaria de Patrimônio da União. Com base nos principais 
instrumentos estabelecidos pela lei n. ${ }^{\circ}$ 7.661/1988 (Plano Nacional de Gerenciamento Costeiro), regulamentada pelo Decreto n. $^{\circ} 5.300$ de 2004, o projeto apresenta. entre seus objetivos, o fortalecimento da articulação dos atores do setor público e aperfeiçoamento de normas existentes para o ordenamento de usos e ocupação desse espaço. Prioriza o estímulo de ações e esforços para a mobilização social, que levam ao desenvolvimento sustentável na orla. Este projeto prevê o ordenamento da faixa marítima de 50 metros em áreas com urbanização consolidada, e 200 metros para as demais áreas, observando-se as peculiaridades de cada local, podendo exigir o aumento ou o recuo da largura dessa faixa para a gestão sustentável da orla (PROJETO ORLA, 2006).

\section{Área de estudo}

O canal da Barra da Lagoa (Figura 1), com cerca de $2,5 \mathrm{~km}$ de comprimento, localiza-se na porção centroleste da Ilha de Santa Catarina, Brasil (lat. 27³4' S, long. $48^{\circ} 25^{\prime}$ O) e comunica a Lagoa da Conceição com o Oceano Atlântico (SIERRA DE LEDO e SORIANO-SIERRA, 1999). Com população de 3.533 habitantes e área total de 427 hectares (IBGE, 2000), o distrito de Barra da Lagoa faz limite ao norte e ao sul, respectivamente, com os distritos de São João do Rio Vermelho e Fortaleza da Barra, a leste com o Oceano Atlântico e a Oeste com a Lagoa da Conceição.

FIGURA 1 - LOCALIZAÇÃO DO CANAL DA BARRA DA LAGOA, ILHA DE SANTA CATARINA.

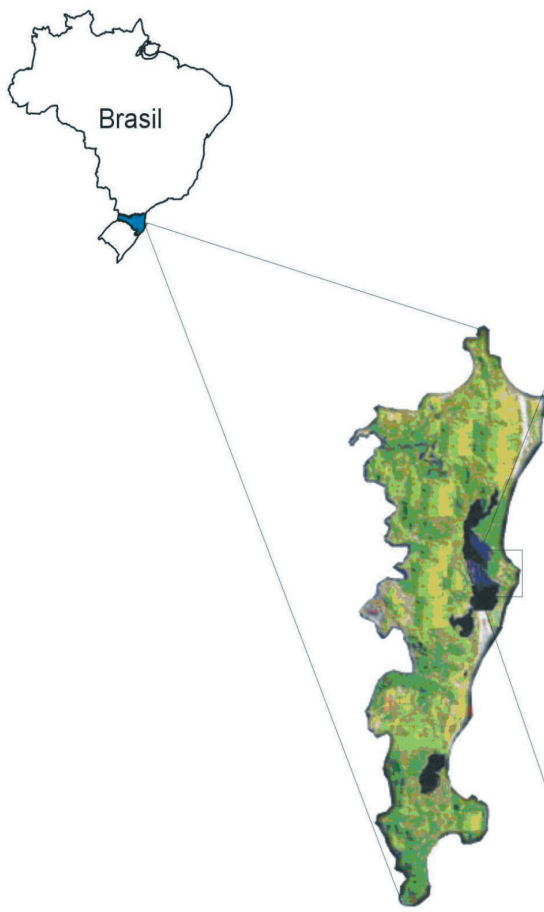

Ilha de Santa Catarina

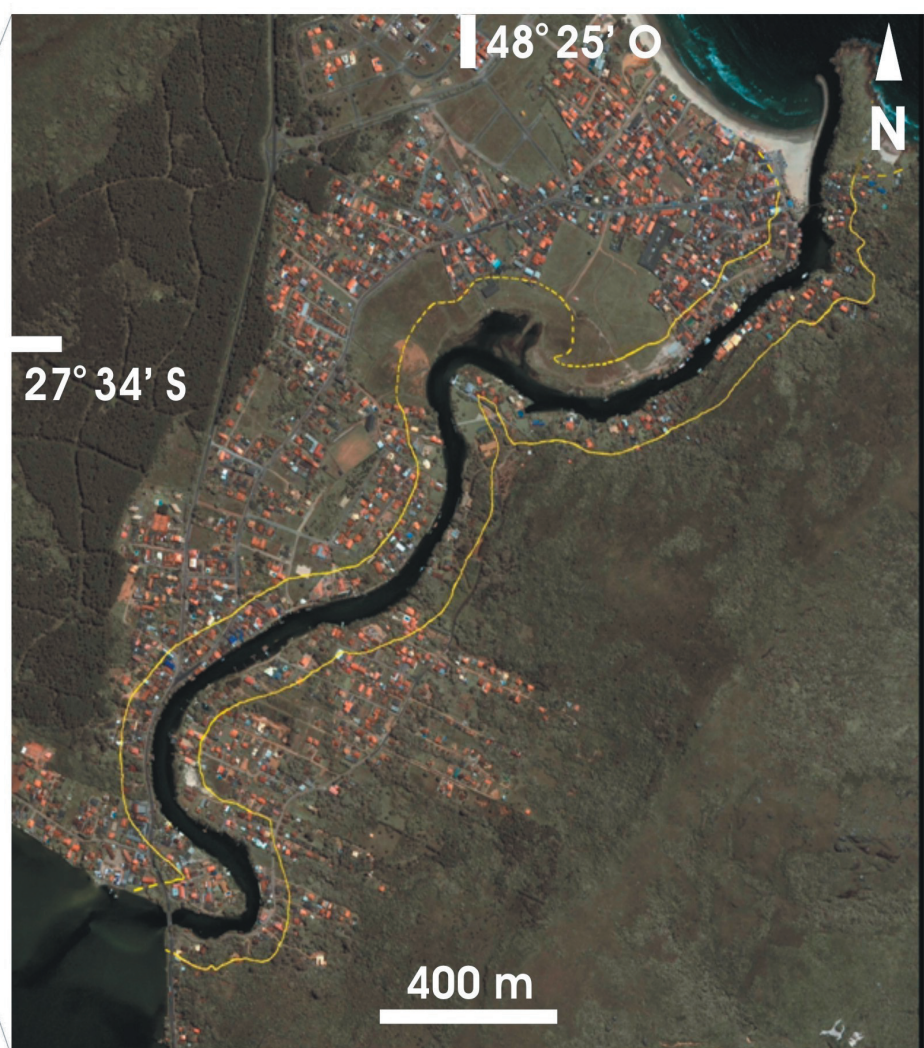




\section{Atores sociais}

Neste estudo, entende-se por "atores sociais" as pessoas que usam e ocupam o entorno do canal lagunar, residindo permanente ou com propriedade secundária; atores pertencentes a instituições não-governamentais e pessoas com cargo de grande responsabilidade nas ONGs atuantes na bacia hidrográfica da área de estudo, assim como funcionários que atuam em instituições governamentais ambientais e instituições com atribuições sobre a área, ocupantes de cargos de responsabilidade.

\section{Metodologia}

Para a realização do presente trabalho, utilizou-se a metodologia de Estudo de Caso segundo Yin (2001). Para isto, durante os anos de 2004 e 2005, foram aplicadas entrevistas estruturadas conforme Marconi e Lakatos (1990) e Gil (1994) na comunidade local e com pessoas-chave que fazem parte das instituições não-governamentais e governamentais.

Para a seleção dos entrevistados na constituição da amostra desta pesquisa, optou-se por trabalhar, na comunidade da Barra da Lagoa, com amostragem por acessibilidade, onde o pesquisador seleciona os elementos aos que tem acesso, admitindo que são representativos do universo delimitado, enquanto que com os atores institucionais, a amostra foi intencional. Assim, utilizouse dos seguintes critérios: 1) na comunidade local, os atores que usam ou ocupam a orla do canal, incluindo pescadores, proprietários de estaleiros, proprietários de restaurantes e bares, de pousadas, de peixarias e de residências de aluguel para turistas de verão e finais de semana; 2) nas instituições não-governamentais, as que atuam na bacia hidrográfica da Lagoa da Conceição, onde o canal está localizado; 3) dentre os atores governamentais, os que têm atribuição sobre a área citada, conforme o Quadro 1.

QUADRO 1 - ATORES ENTREVISTADOS PARA A REALIZAÇÃO DO ESTUDO DE CASO.

\begin{tabular}{|c|c|c|c|c|}
\hline $\begin{array}{l}\text { Comunidade } \\
\text { Local } \\
\text { (51) }\end{array}$ & $\begin{array}{c}\text { Instituições } \\
\text { Não-govemamentais } \\
(16)\end{array}$ & \multicolumn{3}{|c|}{$\begin{array}{c}\text { Instituições Govemamentais } \\
\qquad(\mathbf{4 0 )}\end{array}$} \\
\hline $\begin{array}{l}\text { Familias de } \\
\text { pescadores (26) } \\
\text { Proprietários de } \\
\text { estaleiros (1) } \\
\text { Proprietários de } \\
\text { restaurantes e } \\
\text { bares (6) } \\
\text { Proprietários de } \\
\text { pousadas (11) } \\
\text { Proprietários de } \\
\text { peixarias (2) } \\
\text { Proprietários de } \\
\text { residências de } \\
\text { veraneio e final de } \\
\text { semana (5) }\end{array}$ & $\begin{array}{c}\text { Conselho } \\
\text { comunitário (2) } \\
\text { Sindicato dos } \\
\text { Pescadores de SC (1) } \\
\text { Fórum da Barra (2) } \\
\text { Colônia de } \\
\text { Pescadores Z11 (2) } \\
\text { Associação dos } \\
\text { Moradores da Lagoa (1) } \\
\text { Associação de Vela } \\
\text { Associação dos } \\
\text { Moradores do Canto } \\
\text { da Lagoa (2) } \\
\text { Associação dos } \\
\text { Moradores da Bacia } \\
\text { da Lagoa (1) } \\
\text { SOS Praia Mole (1) } \\
\text { Comitê da Bacia da } \\
\text { Lagoa da Conceição (3) } \\
\text { Fundação Lagoa (1) }\end{array}$ & $\begin{array}{c}\text { MUNICIPAIS } \\
\text { Fundação Municipal } \\
\text { do Meio Ambiente (3) } \\
\text { Secretaria de } \\
\text { Urbanização de } \\
\text { Serviço Público (3) } \\
\text { Instituto de } \\
\text { Planejamento Urbano } \\
\text { de Florianópolis (3) } \\
\text { Intendência da Barra } \\
\text { da Lagoa (2) } \\
\text { Câmara de Vereadores } \\
\text { Municipal - Comissão } \\
\text { do Meio Ambiente (1) } \\
\text { Conselho Comunitário } \\
\text { de Segurança da Barra } \\
\text { da Lagoa (3) } \\
\text { Secretaria Municipal } \\
\text { de Turismo, Cultura e } \\
\text { Esportes (1) }\end{array}$ & $\begin{array}{c}\text { ESTADUAIS } \\
\text { Ministério Público do } \\
\text { Meio Ambiente de } \\
\text { Santa Catarina (2) } \\
\text { Fundação do Meio } \\
\text { Ambiente (4) } \\
\text { Secretaria de Estado } \\
\text { de Desenvolvimento } \\
\text { Social (3) } \\
\text { Comissão do Meio } \\
\text { Ambiente da } \\
\text { OAB/SC (2) }\end{array}$ & $\begin{array}{c}\text { FEDERAIS } \\
\text { (COM SEDE NO } \\
\text { ESTADO DE SC) } \\
\text { Instituto Brasileiro do } \\
\text { Meio Ambiente (4) } \\
\text { Secretaria Regional } \\
\text { do Patrimônio da } \\
\text { União/SC (5) } \\
\text { Ministério Público } \\
\text { Federal (2) } \\
\text { Instituto do } \\
\text { Patrimônio Histórico } \\
\text { Nacional (1) } \\
\text { Marinha do Brasil } \\
\text { (Capitania dos } \\
\text { Portos) (1) }\end{array}$ \\
\hline
\end{tabular}

FONTE: Bitencourt (2005)

* Entre parêntesis é indicado o número de entrevistados. 


\section{Resultados e discussão}

O canal da Barra da Lagoa tem influência em toda a comunidade, seja para o trabalho, circulação das pessoas, lazer e contemplação, estando presente no cotidiano da população. Assim, a orla do canal é usada para diversos fins, porém, as percepções são diferentes conforme a visão dos atores.

Atores da comunidade local: entre os atores locais (Quadro 1), 90\% demonstraram ter algum conhecimento sobre o que constituem os terrenos de marinha e sua relevância. Quando questionados sobre a importância da sua existência, 53\% não souberam o que responder, sendo que alguns disseram que eram terras da União e que por isso eram importantes. 30\% responderam ser importantes pela sua localização próxima da praia, "local em que muitas pessoas querem morar". Apenas $17 \%$ responderam que são importantes e que devem ser respeitados em função da preservação do meio ambiente.

Atores das organizações não-governamentais: os atores pertencentes às instituições não-governamentais entrevistados (Quadro 1) sabem o que são os terrenos de marinha e 70\% afirmaram que a orla do canal é Área de Preservação Permanente (APP). Dentre estes atores, $80 \%$ responderam que a orla deve ser preservada para a proteção do meio ambiente, embora seja um consenso que não há como preservar e sim como conservar, pois a ocupação do entorno do canal já está consolidada.

As respostas mais representativas da opinião das ONGs sobre a importância da proteção do canal e seu entorno, destacam que estes devem ser respeitados para a preservação ambiental e preservação da vegetação, visando não assorear o canal, sendo que deveriam ser conservados não apenas os $33 \mathrm{~m}$, pois pode não ser o suficiente, podendo o mar invadir os terrenos. Além do mais, estes atores destacam que são importantes para todos os que usam a orla, e que para estes deve ser garantida a livre circulação, sendo que hoje não há, praticamente, acesso às margens. Observou-se também que nas instituições não-governamentais, são muitos os atores que não têm informação sobre os instrumentos que podem regularizar a área da orla do canal da Barra da Lagoa.

Atores institucionais governamentais: todos os atores (Quadro 1) entrevistados têm conhecimento sobre os terrenos de marinha e manifestam ciência da importância da conservação destes. Por lei, os terrenos de marinha podem vir a ser ocupados por terceiros mediante o pagamento de valores conforme estipulado pela União. São bens públicos, porém se incluem dentro da categoria dos "bens públicos dominiais", não sendo considerados pela legislação como bens de uso comum do povo. As respostas elencadas pelos atores institucionais governamentais abordaram a importância da proteção ambiental em primeiro lugar, sendo que $65 \%$ destes responderam serem importantes para proteger o meio ambiente, por constituírem áreas ambientalmente sensíveis e por fazerem parte do patrimônio natural. Por outro lado, percebe-se um equívoco quanto ao uso dos terrenos de marinha, pois $35 \%$ dos entrevistados responderam que são importantes para garantir o acesso público às praias e por serem áreas de uso comum. Neste sentido, os atores sociais institucionais enfatizam a proteção dos terrenos de marinha, destacando nas suas respostas que estes constituem ambientes de transição e de constante erosão, sendo a faixa de marinha a estabilizadora da praia. Além do mais, alegam que é uma área frágil, de transição entre os domínios marinhos e terrestres, sendo vulnerável devido à influência das marés e ressacas, destacando-se que, segundo respondentes, "essa faixa é eventualmente e cada vez mais freqüente tomada pelas águas".

Há respostas que mencionam que é importante conservar os terrenos de marinha porque são bens de uso comum do povo, afirmando que "são ambientes que garantem ao público a circulação e o acesso livre e franco ao mar em qualquer direção e sentido". Além do mais, é citado que "nessa faixa não deve ser construído, é uso público, uso da coletividade".

Os demais atores entrevistados consideram os terrenos de marinha como sendo Área de Preservação Permanente. Há equívocos sobre o conceito de uso destes, o que pode ser ilustrado pela resposta:

Os terrenos de marinha são APP, então é fundamental para nós. As dunas, as margens que estão próximas à orla, as margens dos rios, enfim, tudo aquilo que é considerado como APP é fundamental a preservação para o bem comum. 
A resposta de apenas um dos entrevistados está de acordo com a regulamentação existente, pois esclarece que só no caso em que os terrenos de marinha estiverem sobrepostos a uma área de preservação, aí sim deve, por lei, haver a preservação. Eis a resposta: "Se os terrenos de marinha se sobrepõem a uma área de preservação permanente, deve haver a preservação". Certos atores entrevistados não assumem responsabilidade pela proteção ambiental dos terrenos de marinha. Conforme pode ser verificado pela resposta dada:

Questão de Terrenos de Marinha e Gerenciamento Costeiro eu acho que é uma matéria que é de interesse do Ministério Público Federal. É uma área de competência do Ministério Público Federal, esta questão que você está elencando sobre o aspecto da Barra da Lagoa. Nosso caso aqui é que estamos priorizando as questões ambientais do interior do Estado.

Os terrenos de marinha são reconhecidos como Área de Preservação Permanente por mais de 11\% dos entrevistados, o que não é o caso. Acredita-se que este equívoco possa resultar de uma confusão com as áreas de restinga, estas sim sendo APPs e, ainda, da boa intenção dos entrevistados em reforçar a importância da preservação ambiental. Tal equívoco pode resultar pela orla do canal também ser uma APP, em virtude do Código Florestal. Assim, em certos trechos da costa pode haver restingas em áreas que são de terrenos de marinha: as restingas são consideradas como áreas de preservação permanente conforme o Código Florestal (Lei 4.771/1965) e as Resoluções do CONAMA n. ${ }^{\circ}$ 004/1985 e n. ${ }^{\circ}$ 010/1993, que a definem, assim como a Resolução n. ${ }^{\circ}$ 261/1999, que estabelece parâmetros para análise dos estágios sucessionais de vegetação de restinga especificamente para o Estado de Santa Catarina e a Resolução n. ${ }^{\circ}$ 303/2002, que estabelece os parâmetros, definições e limites de Áreas de Preservação Permanente.

\section{Considerações finais}

O presente estudo mostra que o desconhecimento das leis, da função e poder de execução da atribuição dos diversos atores gestores e institucionais e tomadores de decisão, da comunidade local sobre as questões ambientais relativas ao Canal da Barra da Lagoa, que lhes afeta, são fatores que levam ao incremento das ações impactantes sobre o meio ambiente.

Embora os atores das instituições governamentais considerem que a área da orla do canal deva ser conservada, não houve por parte deles uma ação que coibisse as ocupações que têm acontecido a cada ano, pois foi constatado que têm surgido novas construções na orla do canal, sejam de casas populares, de alto padrão, trapiches particulares, além de muros e cercas privatizando o que é de domínio público.

Toda a ocupação deu-se com a existência de diversos instrumentos de regulamentação que se aplicam ao ordenamento da orla, mas que, na verdade eles não contribuíram para o ordenamento e conservação ambiental do local. Embora a visão dos atores sociais entrevistados seja a de considerar importante a conservação dos terrenos de marinha, a área de estudo apresenta uma situação caótica. Foi evidenciado, ainda, que a estrutura dos atores governamentais com influência sobre a orla do canal não é suficiente para conter a degradação do mesmo.

O Projeto de Gestão Integrada da Orla Marítima - Projeto Orla - é um instrumento que deveria ser implementado na orla do canal da Barra da Lagoa para contribuir à solução do problema, pois este visa, entre outras questões, a gestão democrática da orla. É um projeto que vem proporcionar a articulação entre os diversos atores institucionais e a sociedade. Este é um instrumento que pode promover a gestão ambiental da orla marítima com ações voltadas ao uso e ocupação de forma sustentável. 


\section{Referências}

BITENCOURT, N. de L. da R. A problemática da conservação ambiental dos terrenos de marinha: o caso da Orla do Canal da Barra da Lagoa, Ilha de Santa Catarina, Brasil. Florianópolis, Tese de Doutorado, UFSC, 2005.

BRASIL. Lei $n^{\circ} 11.481$, de 31 de maio de 2007. Dá nova redação a dispositivos das Leis $\mathrm{n}^{\text {os }} 9.636$, de 15 de maio de $1998,8.666$, de 21 de junho de 1993, 11.124, de 16 de junho de 2005, 10.406, de 10 de janeiro de 2002 - Código Civil, 9.514, de 20 de novembro de 1997, e 6.015, de 31 de dezembro de 1973 , e dos Decretos-Leis $n^{\text {os }} 9.760$, de 5 de setembro de 1946, 271, de 28 de fevereiro de 1967, 1.876, de 15 de julho de 1981, e 2.398, de 21 de dezembro de 1987; prevê medidas voltadas à regularização fundiária de interesse social em imóveis da União; e dá outras providências. Brasília: DOU de $31 / 5 / 2007$.

Decreto $n^{\circ}$. 5.300, de 7 de dezembro de 2004. Regulamenta a Lei no 7.661, de 16 de maio de 1988, que institui o Plano Nacional de Gerenciamento Costeiro - PNGC, dispõe sobre regras de uso e ocupação da zona costeira e estabelece critérios de gestão da orla marítima, e dá outras providências. Brasília: DOU de 8/12/2004.

Lei $n^{\circ}$ 10.406, de 10 de janeiro de 2002. Institui o Código Civil. Brasília: DOU de 11/1/2002.

. Constituição da República Federativa do Brasil, de 5 de outubro de 1988. 11. ed. São Paulo: Atlas, 1998.

Lei $n^{\circ}$ 7.661, de 16 de maio de 1988. Institui o Plano Nacional de Gerenciamento Costeiro e dá outras providências. Brasília: DOU de 18/5/1988.

. Lei $n^{\circ} 4.771$, de 15 de setembro de 1965. Institui o novo Código Florestal. Brasília: Presidência da República Subchefia para Assuntos Jurídicos, 1965.

Decreto-Lei $n$ 9.760, de 5 de setembro de 1946. Dispõe sobre imóveis da União e dá outras providências. Rio de Janeiro: DOU de 6/9/1946.

CAZETTA, L. C. Legislação Imobiliária da União: anotações e comentários às leis básicas. Brasília: Ministério do Planejamento, Orçamento e Gestão, Secretaria do Patrimônio da União, 2002.

CONSELHO NACIONAL DO MEIO AMBIENTE - CONAMA. Resolução $n{ }^{\circ}$ 004, de 18 de setembro de 1985. Brasília: D.O.U. de 20/1/86.

. Resolução n. ${ }^{\circ}$ 261, de 30 de junho de 1999. Brasília, Ofício ${ }^{\circ} 1.108$ de 1999.
Resolução n. ${ }^{\circ}$ 10, de $1 .^{\circ}$ de outubro de 1993. Brasília: DOU de 03 de 11 de 1993.

. Resolução n. ${ }^{\circ} 303$, de 20 de março de 2002. Brasília: DOU $13 / 05 / 2002$.

DI PIETRO, M. S. Z. Direito administrativo. São Paulo: Atlas, 1994.

GASPARINI, D. Direito administrativo. São Paulo: Saraiva, 1992.

GIL, Antônio Carlos. Métodos e técnicas de pesquisa social. 4. ed. São Paulo: Atlas, 1994.

INSTITUTO BRASILEIRO DE GEOGRAFIA E ESTATÍSTICA (IBGE). Censo Demográfico 2000: características da população e dos domicílios, resultado do universo. Rio de Janeiro: IBGE, 2000. 520 p.

MARCONI, M. de A.; LAKATOS, E. M. Técnicas de pesquisa: planejamento e execução de pesquisas, amostragens e técnicas de pesquisa, elaboração, análise e interpretação de dados. 2. ed. São Paulo: Atlas, 1990.

MEIRELLES, Hely Lopes. Direito administrativo brasileiro. São Paulo: Malheiros, 1994.

PROJETO ORLA. Fundamentos para a gestão integrada. Ministério do Meio Ambiente, Ministério do Planejamento, Orçamento e Gestão. Brasília: MMA, 2006.

PUGLIESE, R. J. O patrimônio imobiliário da União Federal e o ordenamento jurídico. Disponível em: <http: //geodesia.ufsc.br/ Geodesia-online/index2006.htm>. Acesso em: 12 dez. 2006.

SANTOS, R. de S. Terras de marinha. Rio de Janeiro: Forense, 1985.

SAULE JÚNIOR, N.; BARBOSA, M.; LEVY PIZA FONTES, M.; MENCIO, M. Manual de regularização fundiária em terras da União. São Paulo: Instituto Polis; Brasília: Ministério do Planejamento, Orçamento e Gestão, 2006.

SIERRA DE LEDO, B.; SORIANO-SIERRA, E.J. (Eds.). O ecossistema da Lagoa da Conceição. Ser. Contr. Cient. FEPEMA, 1999.

YIN, Robert K. Estudo de Caso: planejamento e métodos. 2.ed. Porto Alegre: Bookman, 2001. 